\title{
Creep of Single Crystals of Nickel-Based Superalloys at Ultra-High Homologous Temperature
}

\author{
ALEXANDER EPISHIN, BERNARD FEDELICH, GERT NOLZE, SINA SCHRIEVER, \\ TITUS FELDMANN, MUHAMMAD FARZIK IJAZ, BERNARD VIGUIER, \\ DOMINIQUE POQUILLON, YANN LE BOUAR, ANTOINE RUFFINI, \\ and ALPHONSE FINEL
}

The creep behavior of single crystals of the nickel-based superalloy CMSX-4 was investigated at $1288{ }^{\circ} \mathrm{C}$, which is the temperature of the hot isostatic pressing treatment applied to this superalloy in the industry. It was found that at this super-solvus temperature, where no $\gamma^{\prime}$-strengthening occurs, the superalloy is very soft and rapidly deforms under stresses between 4 and $16 \mathrm{MPa}$. The creep resistance was found to be very anisotropic, e.g., the creep rate of [001] crystals was about 11 times higher than that of a [111] crystal. The specimens of different orientations also showed a very different necking behavior. The reduction of the cross-sectional area $\psi$ of [001] crystals reached nearly 100 pct, while for a [111] crystal $\psi=62$ pct. The EBSD analysis of deformed specimens showed that despite such a large local strain the [001] crystals did not recrystallize, while a less deformed [111] crystal totally recrystallized within the necking zone. The recrystallization degree was found to be correlated with deformation behavior as well as with dwell time at high temperature. From the analysis of the obtained results (creep anisotropy, stress dependence of the creep rate, traces of shear deformation, and TEM observations), it was concluded that the main strain contribution resulted from $\langle 01 \overline{1}\rangle\{111\}$ octahedral slip.

https://doi.org/10.1007/s11661-018-4729-6

(C) The Minerals, Metals \& Materials Society and ASM International 2018

\section{INTRODUCTION}

SINGLE-CRYSTAL nickel-based superalloys are used as blade materials for gas turbine aircraft engines and land-based gas turbines of power plants. These superalloys contain no large angle boundaries, which excludes intergranular oxidation and rupture. Nevertheless, the industrial technology of manufacturing of single-crystal blades cannot avoid the formation of micropores,${ }^{[1]}$ which significantly deteriorate the fatigue strength. Therefore, the advanced blade producers remove this structural defect by hot isostatic pressing (HIP), see e.g., Reference 2. The blades are usually

ALEXANDER EPISHIN is with the Technical University of Berlin, Berlin, Germany. Contact e-mail: a.epishin@tu-berlin.de BERNARD FEDELICH, GERT NOLZE, SINA SCHRIEVER, and TITUS FELDMANN are with the Federal Institute for Materials Research and Testing (BAM), Berlin, Germany. MUHAMMAD FARZIK IJAZ, BERNARD VIGUIER, and DOMINIQUE POQUILLON are with the CIRIMAT/ University of Toulouse, Toulouse, France. YANN LE BOUAR, ANTOINE RUFFINI, and ALPHONSE FINEL are with the Laboratoire d'Etude des Microstructures, CNRS/ONERA (LEM), Châtillon, France.

Manuscript submitted March 14, 2018.

Article published online June 13, 2018
HIPed at temperatures between $\gamma^{\prime}$-solvus and solidus where superalloy has no strengthening $\gamma^{\prime}$-phase and therefore is very soft. For example, the company Howmet Castings HIPs the superalloy CMSX-4*33 at

$* \mathrm{CMSX}-4^{\circledR}$ is registered trademark of the Cannon Muskegon Corporation.

the temperature $1288{ }^{\circ} \mathrm{C}(1561 \mathrm{~K})$, which corresponds to a homologous temperature of about $0.97=1561 \mathrm{~K} /$ $1613 \mathrm{~K}$ (denominator is solidus temperature). Data about the creep behavior of metals and their alloys at such high temperatures are very limited. The reason is that most engineering alloys are used at temperatures below 0.6 to 0.8 of their melting point. For single-crystal nickel-based superalloys that operate at temperatures up to $\left[1100{ }^{\circ} \mathrm{C}\right.$ to $1150{ }^{\circ} \mathrm{C}(1373 \mathrm{~K}$ to $\left.1423 \mathrm{~K})\right]$, the homologous temperature is higher, 0.85 to 0.88 . Because of the possibility of technical accidents resulting in overheating, creep of superalloys at higher temperatures is also investigated, e.g., in References 4,5 at $1200{ }^{\circ} \mathrm{C}$ $(1473 \mathrm{~K})$ which corresponds to homologous temperature of about 0.91. But even this temperature is significantly lower than that applied during HIP. HIP is a costly technological process, which bears the risk of 
recrystallization and incipient melting of the expensive single-crystal blades. Therefore, the parameters of industrial HIP (temperature $T$, pressure $p$, duration $t$ ) must be carefully optimized to ensure full pore healing without material damage and minimal processing costs. Understanding the material behavior under HIP conditions and modeling pore closure during HIP could help to optimize these parameters.

The objective of the present work was to investigate the creep behavior of single-crystal nickel-based superalloy CMSX-4 at the temperature of commercial HIP $1288^{\circ} \mathrm{C}$. The focus lies on the creep kinetics, the creep anisotropy, the deformation mechanisms, and the recrystallization behavior. The data obtained in this work have been used in an elastoviscoplastic model describing the kinetics of porosity annihilation in CMSX-4 during commercial HIP. ${ }^{[6,7]}$

\section{EXPERIMENTAL}

\section{A. Investigated Material}

The investigated material is the single-crystal nickel-based superalloy CMSX-4 widely used as blades material for aircraft and land-based gas turbines. The composition is given in Reference 8. In the 1st testing series of this work, CMSX-4 single-crystal cylindrical bars with [001] orientation solidified by Howmet Castings Alcoa were used. The 2nd testing series was performed with single-crystal cylindrical bars of Doncasters Precision Castings Bochum, having different orientations, namely, [001], [011], [111], and [123]. All bars were solidified from the master alloy of CMSX-4 supplied by the Cannon Muskegon Corporation. The chemical composition of the master alloy was within the tolerance defined by this company. After casting, the bars received the standard heat treatment including the multistep solution cycle, ${ }^{[9]}$ followed by the 1 st aging cycle $1140{ }^{\circ} \mathrm{C} / 6$ hours and the 2 nd aging cycle $871{ }^{\circ} \mathrm{C} / 20$ hours.

The crystallographic orientations of the bars were measured by the producers using X-ray diffraction (XRD) as well as in our group by a metallographic method, as described in Reference 10. In the second case, the Euler angles $\theta$ and $\rho$ were calculated from the directions of the dendritic arms observed on the bar surfaces before testing. The dendritic structure was revealed by etching the specimens with hydrochloric acid 37 pct and small additions of hydrogen peroxide activating reaction $2 \mathrm{HCl}+\mathrm{H}_{2} \mathrm{O}_{2}=2 \mathrm{H}_{2} \mathrm{O}+\mathrm{Cl}_{2} \uparrow$ releasing free chlorine reacting with metal. Two photographs of the surface were taken from the etched cylindrical bars. The bar was rotated by 90 deg before taking the second photograph. An advantage of the metallographic method is that the orientation is measured in the bar middle, corresponding to the gage length of the machined creep specimen. In the XRD method, the orientation is usually measured at the end of the bar and can differ from the middle due to the subgrain structures that typically exist in "technical single crystals" of nickel-based superalloys. The Euler angles $\theta$ and $\rho$ determined by XRD and metallography are presented in Table I. The difference between the results of these two measurements is typically equal to 1 to $3 \mathrm{deg}$, which is comparable to the misorientation induced by the subgrain structures in superalloy single crystals, see e.g., References 11, 12.

For HIPing, the dissolution of the strengthening $\gamma^{\prime}$-precipitates at the processing temperature of $1288^{\circ} \mathrm{C}$ is crucial. The $\gamma^{\prime}$-content in CMSX-4 as function of the temperature was investigated by three methods: electrical resistivity measurement, calorimetry, and dilatometry. The $\gamma^{\prime}$-solvus temperature was determined by the breakpoints of the curves $\rho=f(T), \quad c=f(T)$, and

Table I. Testing Conditions: Size and Crystallographic Orientation of the Creep Specimens, Applied Stress $\sigma$, Testing Time $t$, Creep Strain $\varepsilon$, and Reduction of Cross-Sectional Area $\psi$

\begin{tabular}{|c|c|c|c|c|c|c|c|c|c|c|c|c|}
\hline \multirow{4}{*}{$\begin{array}{l}\text { Bar, } \\
\text { Test No. }\end{array}$} & \multirow{4}{*}{$\begin{array}{l}\text { Testing } \\
\text { Series }\end{array}$} & \multirow[b]{4}{*}{ Sizes, mm } & \multicolumn{5}{|c|}{ Orientation } & \multirow[b]{4}{*}{$\sigma, \mathrm{MPa}$} & \multirow[b]{4}{*}{$t, \mathrm{~h}$} & \multirow[b]{4}{*}{$\varepsilon, \operatorname{Pct}$} & \multirow[b]{4}{*}{$\psi$, Pct } & \multirow{4}{*}{$\begin{array}{l}\text { End of } \\
\text { Testing }\end{array}$} \\
\hline & & & \multirow[b]{3}{*}{$\approx[\mathrm{hkl}]$} & \multicolumn{4}{|c|}{ Euler Angles } & & & & & \\
\hline & & & & \multicolumn{2}{|c|}{ XRD } & \multicolumn{2}{|c|}{ Metallogr. } & & & & & \\
\hline & & & & $\theta$, Deg & $\rho$, Deg & $\theta$, Deg & $\rho$, Deg & & & & & \\
\hline 1 & 1 & $\varnothing 14.5 \times 170$ & [001] & 7.2 & - & 6.1 & 24.4 & 4 & 49.3 & 2.6 & 5.5 & interruption \\
\hline 2 & & $\varnothing 14.5 \times 170$ & [001] & 6.6 & - & 4.4 & 21.3 & 6 & 6.2 & 9.1 & 13 & interruption \\
\hline 3 & & $\varnothing 14.5 \times 170$ & {$[001]$} & 6.6 & - & 6.4 & 26.4 & 8 & 1.4 & 3.4 & 4 & interruption \\
\hline 4 & & $\widetilde{\varnothing} 14.5 \times 170$ & [001] & 4.1 & - & 0.4 & 20.9 & 10 & 1.2 & 11.3 & - & interruption \\
\hline 5 & & $\varnothing 14.5 \times 170$ & [001] & 4.8 & - & 2.0 & 0.0 & 13 & 0.3 & 14.0 & 15 & interruption \\
\hline 6 & & $\varnothing 14.5 \times 170$ & [001] & 4.6 & - & 1.7 & 44.8 & 16 & 0.2 & 13.9 & 16.5 & interruption \\
\hline 7 & 2 & $\varnothing 8 \times 115$ & [001] & 4.7 & 36.2 & 4.5 & 38.5 & 10 & 2.2 & 46.7 & $99.8^{*}$ & rupture \\
\hline 8 & & $\varnothing 8 \times 115$ & [011] & 42.3 & 1.6 & 41.4 & 0.0 & 10 & 7.0 & 14.5 & $83^{*}$ & rupture \\
\hline 9 & & $\varnothing 8 \times 115$ & [123] & 34.6 & 18.9 & 38.0 & 24.1 & 10 & 6.6 & 16.7 & $92 *$ & rupture \\
\hline 10 & & $\varnothing 8 \times 115$ & [111] & 42.3 & 40.4 & 46.5 & 39.8 & 10 & 22.2 & 33.4 & $62 *$ & rupture \\
\hline 11 & & $\varnothing 8 \times 115$ & [011] & 41.5 & 2.5 & - & - & 10 & 2.9 & 5.1 & 4.8 & interruption \\
\hline
\end{tabular}

*Measured after rupture, '-' no measurement. 
$\varepsilon_{T}=f(T)$, where $\rho, c$, and $\varepsilon_{T}$ are, respectively, the specific electrical resistivity, the specific heat capacity, and the linear thermal expansion. The measurements yielded the following values for the $\gamma^{\prime}$-solvus temperature: $1280{ }^{\circ} \mathrm{C}, 1276^{\circ} \mathrm{C}$, and $1280^{\circ} \mathrm{C}$, respectively. Therefore, it can be assumed that above $1280^{\circ} \mathrm{C}$ the $\gamma^{\prime}$-content is either vanishing or at most very low. This issue was also investigated in more details by metallographic inspection of a crept specimen (see Section III-D).

\section{B. Creep Tests}

The creep tests were performed in air at $1288^{\circ} \mathrm{C}$ in constant load arm machines equipped by resistive ATS-furnaces with $\mathrm{SiC}$ heating elements operating up to $1500{ }^{\circ} \mathrm{C}$. The hot zone of these furnaces is short, about $75 \mathrm{~mm}$, but within the specimen gage of length 25 $\mathrm{mm}$ the temperature field is quite uniform with a temperature difference between gage center and ends less than $5^{\circ} \mathrm{C}$. The longitudinal creep strain was measured within this $25-\mathrm{mm}$ gage length with an axial MTS-extensometer protected from radiation by a water-cooled shield, which allows to use it up to $1450{ }^{\circ} \mathrm{C}$. The tests were performed in two series. The 1 st series included interrupted creep tests of long, thick [001] oriented specimens with a total length of $170 \mathrm{~mm}$ and a gage diameter of $14.5 \mathrm{~mm}$, tested under tension at 4, 6, 8, 10, 13, and $16 \mathrm{MPa}$. Such long specimens were machined to keep the threaded grips made of CMSX-4 outside of the hot zone. The purpose of machining of specimens of the large diameter was to reduce the influence of oxidation on results of tests. The 1st testing series however showed, that both problems are not as critical as expected, i.e., CMSX-4 has good oxidation resistance even at such a high temperature as $1288^{\circ} \mathrm{C}$. Therefore, for the 2 nd testing series, five smaller specimens of total length $115 \mathrm{~mm}$ and diameter $8 \mathrm{~mm}$ were machined. These specimens had axial orientations close to [001], [011], [111], and one approximately [123], so close to the middle of the stereographic triangle. The specimens were tested under a tensile stress of $10 \mathrm{MPa}$. Four specimens, [001], [011], [111], and [123], were tested until rupture, but the test with the second [011] specimen was interrupted at creep strain of about 5 pct and then the specimen was rapidly cooled down under load by a jet of compressed air for freezing the high temperature dislocation configurations. This [011] specimen was used for measurement of the shape change of the specimen cross section, for TEM investigation of the deformation mechanisms as well as for verification of the $\gamma^{\prime}$ dissolution at $1288{ }^{\circ} \mathrm{C}$. Table I summarizes the information about the testing conditions: the specimen geometry, the applied stress $\sigma$, the testing time $t$, the accumulated creep strain $\varepsilon$, and the reduction of cross-sectional area $\psi$ after the test.

\section{Electron Microscopy}

After the creep tests, specimens of [001], [011], [111], and [123] orientations ruptured in the 2nd testing series (nos. 7 to 10 in Table I) were investigated in a scanning electron microscope FEG-SEM GEMINI 1530 VP (LEO) equipped with a Bruker EDS detector XFlash 5030 and an EBSD detector e-Flash HR with the software ESPRIT and CrystAlign. The main points of interest were traces of the active slip systems and check of the material recrystallization, which is critical for HIPing the single-crystal blades. For the EBSD investigation, the [001], [011], [111] specimens were cut longitudinally along $\{011\}$ planes and the [123] specimen close to $(0 \overline{3} 2)$. The cuts were grinded and polished, where the final step of fine polishing was performed with colloidal silica, necessary to get clear Kikuchi patterns.

For TEM investigations, the specimens numbered as 8 to 11 in Table I were used. From these specimens, the TEM foils were cut, for the [123] specimen parallel to the longitudinal plane $(0 \overline{3} 2)$, for others parallel to the

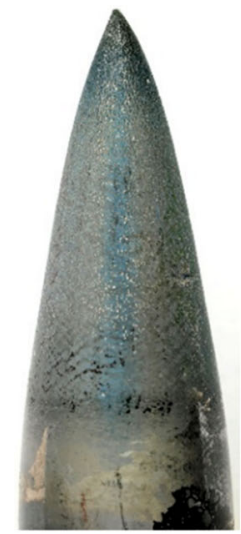

(100)

[001]

(a)

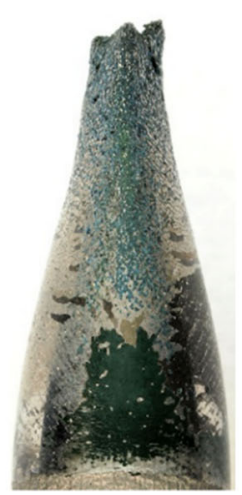

$(01 \overline{1})$

[011]

(b)

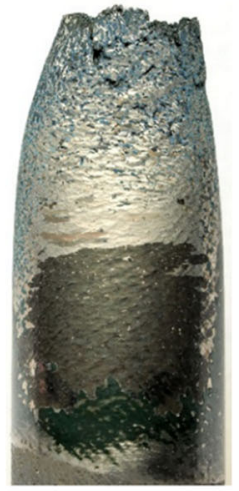

(100)

[011]

(c)

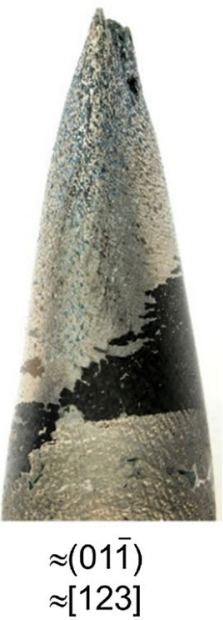

(d)

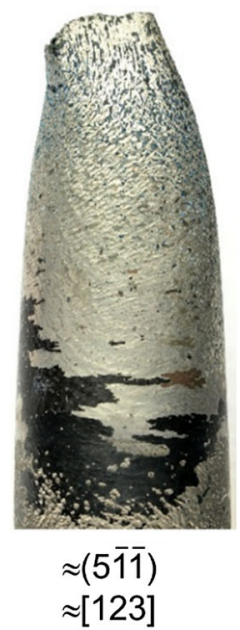

(e)

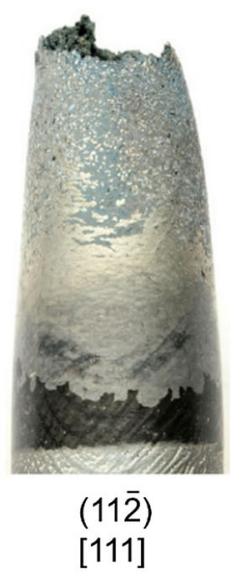

(f)

Fig. 1-Necking behavior of CMSX-4 specimens of different orientations (nos. 7 to 10 in Table I) tested to rupture at $1288^{\circ} \mathrm{C} / 10 \mathrm{MPa}$. $(a)$ - [001], $(b, c)-[011],(d, e)-[123]$, and $(f)$ - [111]. View planes are given under the photos in round brackets. The relative reduction of the cross-sectional area after rupture is respectively $99.8,83,92$, and 62 pct. 
longitudinal planes $\{01 \overline{1}\}$. The foils were electrolytically thinned in an electropolisher Tenupol-3 Struers with electrolyte $10 \mathrm{vol}$ pct perchloric acid, 83 vol pct ethanol, and vol 7 pct glycerin at $-30{ }^{\circ} \mathrm{C}$. The foils were investigated in a TEM Phillips CM30 with respect to the deformation mechanisms, using conventional diffraction contrast.

\section{RESULTS}

\section{A. Shape of Specimens After Creep Tests}

Figure 1 shows the shapes of the ruptured specimens of different orientations (nos. 7 to 10 in Table I). The [001] specimen has a pronounced conical shape (Figure 1(a)), indicating isotropic necking as well as very high local strain with a reduction of the cross-sectional area $\psi=99.8$ pct. High ductility was also shown by the [011] and [123] specimens, with $\psi=83$ pct and $\psi=92$ pct, respectively, but necking of these specimens was very anisotropic. The cross section of the [011] specimen at the rupture surface is strongly thinned in the [100] direction and only a little in the [011] one, compare Figures 1(b) and (c). The shape of the cross section of the [123] specimen is very similar to that of the [011] one. It is also strongly thinned in a direction close to [011] (Figure 1(d)) and much less in the [511] direction close to [100] (Figure 1(e)). The rupture behavior of the [111] specimen (Figure 1(f)) was very different from the others, showing less necking, $\psi=62$ pct, a circular cross section, and a rough rupture surface.

Figure 2 shows the result of a quantitative analysis of the cross-sectional shape of the [011] specimen after creep at $1288{ }^{\circ} \mathrm{C} / 10 \mathrm{MPa}$ interrupted at a creep strain of 5.1 pct (no. 11 in Table I). The specimen was analyzed in a light microscope Zeiss-Axiotech $100 \mathrm{HD}$. In the microscope it was mounted in a special holder that allows to hold a specimen in the horizontal position and rotate it by defined angles around the specimen axis. Rotating the specimen with step 10 deg and measuring the specimen diameter $d$, a function $d=f(\phi)$ was obtained, where $\varphi$ is the angle between the measurement direction and the diametrical direction [100]. The measurements were performed in three positions: in the middle of the specimen gage length and at its ends located $\pm 12 \mathrm{~mm}$ away. The angular dependence was determined by averaging $\bar{d}=\bar{f}(\phi)=\frac{1}{3} \sum_{n=1}^{3} f_{i}(\phi)$, where $i$ means different positions. Such an averaging is necessary for comparison of the experimentally measured cross-sectional shape with the theoretical one calculated from the longitudinal creep strain measured within the extensometer gage length equal to $25 \mathrm{~mm}$ (the theoretical contour of the cross section and its comparison with the experiment will be presented and discussed in Chapter IV below). The results of measurements are presented in Figure 2 (black dots) as an angular function of the radius $r=\bar{d} / 2=\bar{f}(\phi) / 2$. One can see

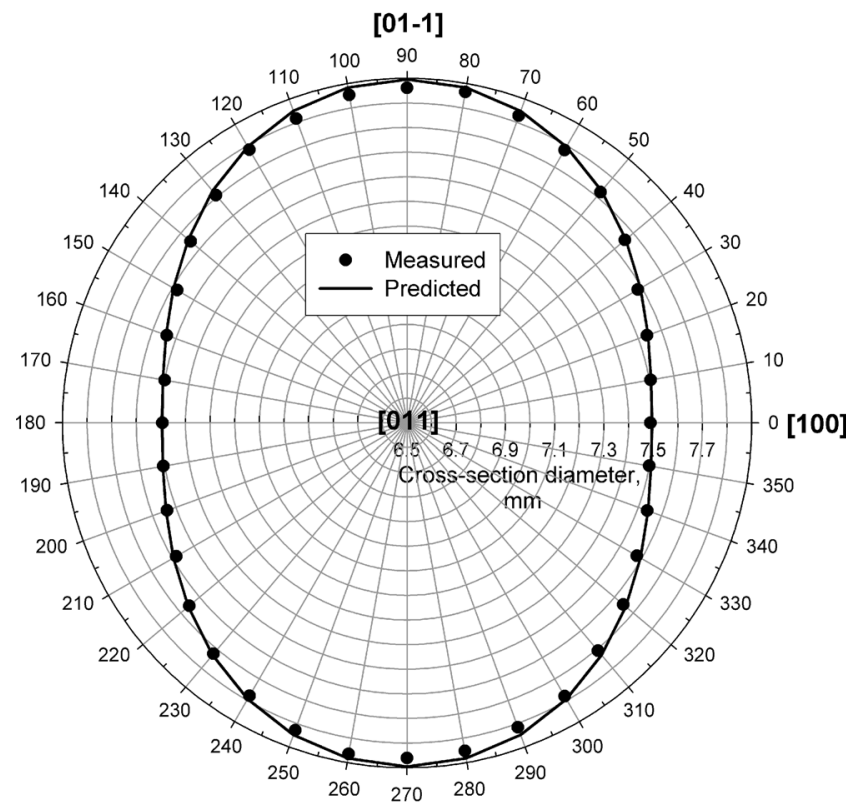

(a)

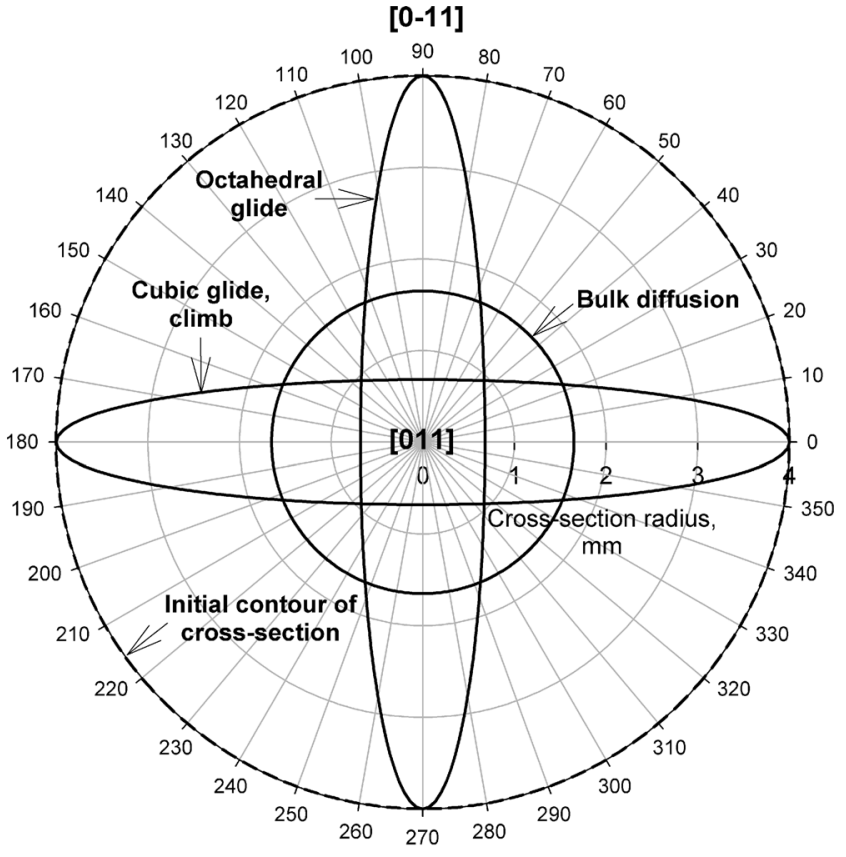

(b)

Fig. 2- Shape of the cross section of [011] specimens tested at $1288{ }^{\circ} \mathrm{C} / 10 \mathrm{MPa}$. (a) Creep test interrupted at train of $\varepsilon_{z z}=5.1$ pct (no. 11 in Table I). The dots correspond to the measurements. The continuous curve is the theoretical prediction assuming octahedral glide. $(b)$ Theoretical predictions for ruptured specimen with reduction of cross-sectional area $\psi=83$ pct (no. 9 in Table I) assuming different creep mechanisms. 
here a clear elliptical shape of the cross section with the longest and shortest diameters, respectively, along [01 $\overline{1}]$ and [100].

\section{B. Creep Behavior}

The creep curves are presented in Figure 3. Figures 3(a) and (b) correspond to the [001] specimens tested under the stress levels 4, 6, 8, 10,13, and $16 \mathrm{MPa}$ (1st testing series). The creep curves have nearly exponential shape and the creep rate depends essentially on the stress level. However, in a different representation, when the time $t$ is normalized by the time $t_{2.5} \mathrm{pct}$ needed for 2.5 pct creep strain, (Figure 4), one can recognize more details of the creep curves. Namely, a primary creep strain $\varepsilon_{1}$ can be measured as well as the minimum creep rate $\dot{\varepsilon}_{\min }$, which is characteristic of the secondary creep stage.

The primary creep $\varepsilon_{1}$ shows a significant scatter (e.g., see two black squares at $10 \mathrm{MPa}$ in Figure 5(a)), probably due to the deviation of the specimen orientations from [001]. But in general, $\varepsilon_{1}$ clearly increases with

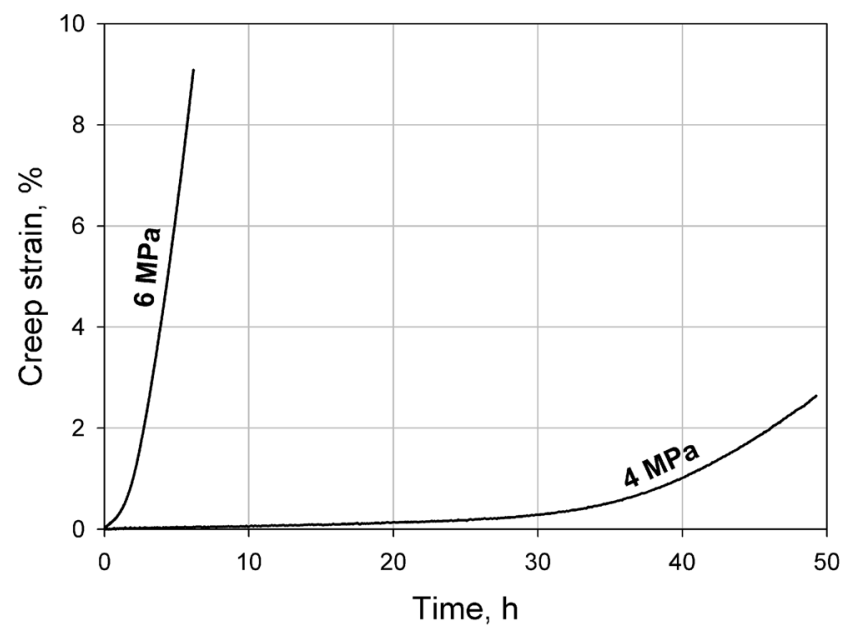

(a) stress $\sigma$ and this increase can be approximated by a linear function of $\sigma$ for the [001] specimens. The minimum creep rate $\dot{\varepsilon}_{\min }$ of the [001] oriented specimens in a double logarithmic plot gives a straight line (Figure 5(b)), i.e., follows the Norton power law $\dot{\varepsilon}_{\min }=$ $A \sigma^{n}$ with a stress exponent $n$ of about 6.4 .

Figure 3(c) shows the creep curves of specimens having different orientations but tested under the same stress level of $10 \mathrm{MPa}$ (2nd testing series). The creep curves have all similar shapes but their slopes are very different. Creep is the slowest for [111] orientation, the fastest for [001], while [011] and [123] are in between. Scaling the creep time for the [001] creep curve by the factor 11.5, one can get a curve (dashed line) being very close to the [111] creep curve, which demonstrates the similarity of the creep curve shapes. Thus, the average creep rates of [001] and [111] specimens differ by 11.5 times! Such a big superiority of the [111] orientation over [001] is not observed at lower temperatures, e.g., according to Reference 13 the ratio of creep lifetime of [111] single crystals of CMSX-4 to that of [001] single crystals does not exceed 3.5 in the temperature interval

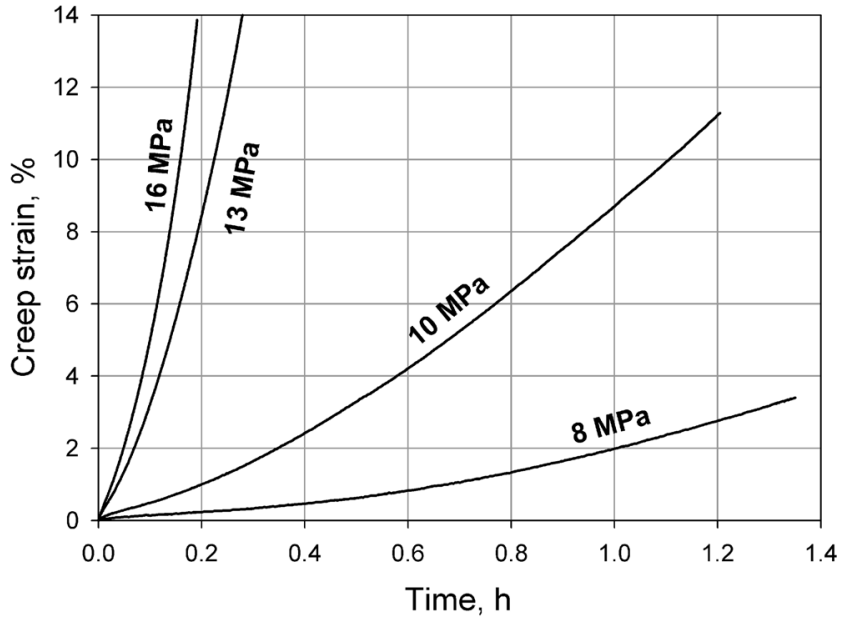

(b)

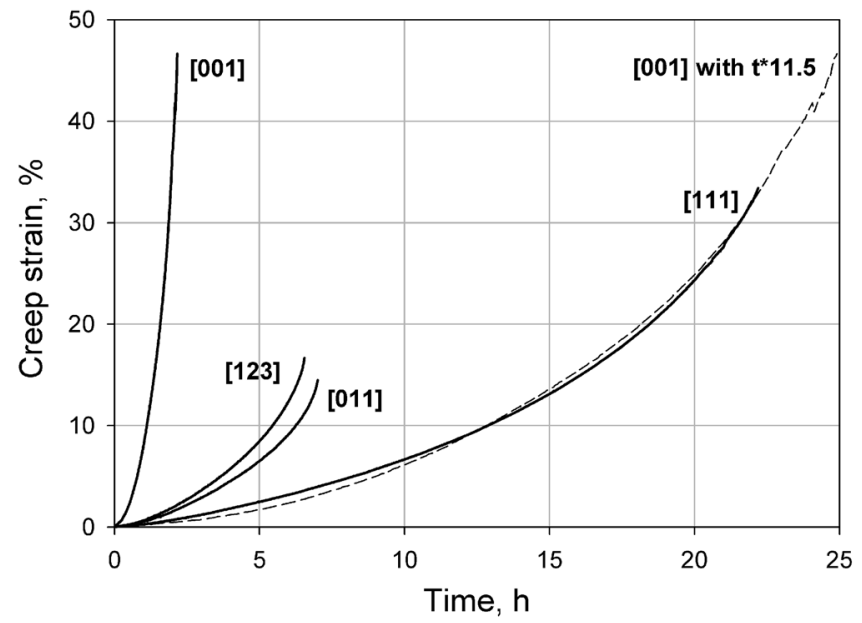

(c)

Fig. 3 - Creep curves of CMSX-4 at $1288^{\circ} \mathrm{C}$. $(a, b)$ The 1st testing series: interrupted creep tests of [001] specimens under 4, 6, 8, 10, 13, and 16 MPa. (c) The 2nd testing series: rupture creep tests of [001], [011], [111], and [123] specimens under $10 \mathrm{MPa}$. 
900 to $1000{ }^{\circ} \mathrm{C}$. The primary creep strain $\varepsilon_{1}$ of the differently orientated specimens shows a corresponding behavior, see Figure 5(a), that is, it increases from [111] to [001].

To investigate whether the observed creep anisotropy can be explained by the crystallography of octahedral slip, the orientation dependence of the stationary (minimum) creep rate $\dot{\varepsilon}_{\text {min }}$ was rationalized assuming deformation by octahedral slip systems. Under the uniaxial stress $\sigma$, the axial strain rate $\dot{\varepsilon}_{\text {min }}$ is the sum of the contributions of the shear creep rates of the 12 octahedral slip systems $\langle 01 \overline{1}\rangle\{111\}$ :

$$
\dot{\varepsilon}_{\min }=\sum_{s=1}^{12} m_{\text {slip }, s} \dot{\gamma}_{s, \min },
$$

where $s$ is the index of the slip system, $m_{\text {slip,s }}$ its Schmid factor, and $\dot{\gamma}_{s, \min }$ its shear creep rate.

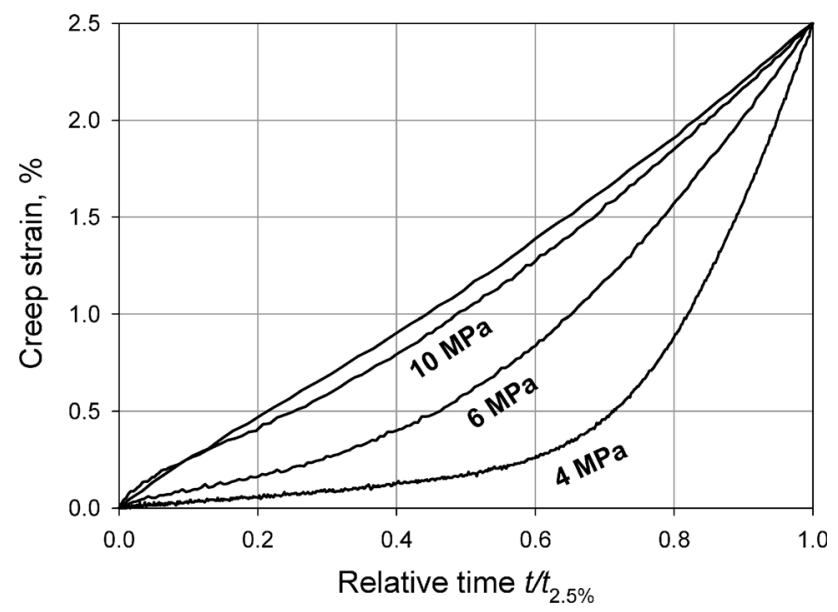

Fig. 4 -Creep strain $v s$ normalized time $t / t_{2.5}$ pct, [001] specimens.

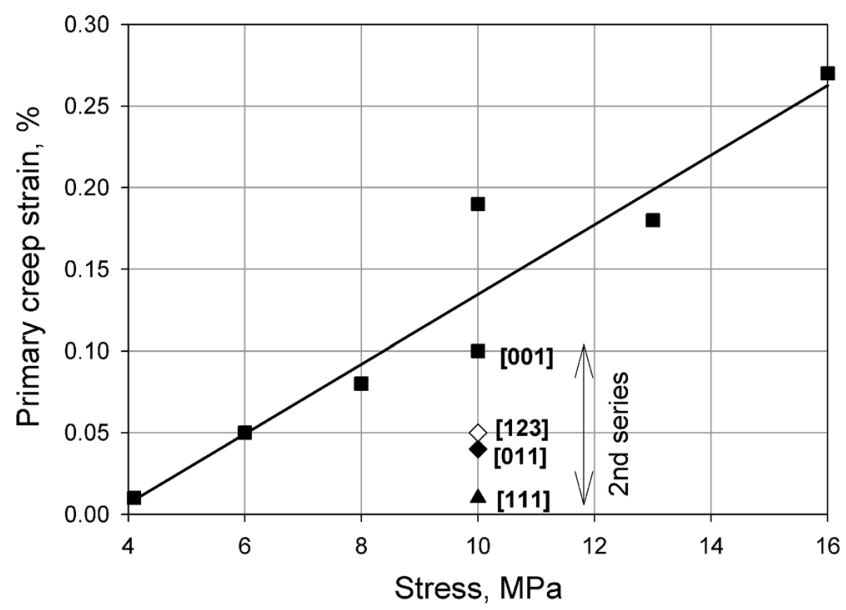

(a)
In a first approximation, the shear kinetics for all slip systems can be described by the Norton power law as follows:

$$
\dot{\gamma}_{s, \min }=A \tau_{s}^{n}
$$

where $\tau_{s}=m_{\text {slip.s }} \sigma$ is the resolved shear stress for the slip system $s$. The material parameters $A$ and $n$ are assumed to be equal for all slip systems. Substituting [2] in [1] one gets:

$$
\dot{\varepsilon}_{\min }=A \sigma^{n} \Phi, \text { with } \Phi=\sum_{s=1}^{12} m_{s l i p, s}^{n+1},
$$

where $\Phi=\Phi(\theta, \rho)$ is a factor that depends on the specimen orientation.

From [3] follows the orientation dependence:

$$
\dot{\varepsilon}_{\min }=A \sigma^{n} \Phi(\theta, \rho)
$$

and the stress dependence:

$$
\dot{\varepsilon}_{\min } \Phi^{-1}=A \sigma^{n}
$$

The obtained orientation dependence is shown in Figure 6(a). It is seen that the tendency, increase of $\dot{\varepsilon}_{\text {min }}$ from [111] to [001], is in accordance with octahedral slip. But $\dot{\varepsilon}_{\text {min }}$ is not a linear function of $\Phi$. After a slow increase of $\dot{\varepsilon}_{\text {min }}$ from [111] to [123] and [011], it then strongly increases to [001].

Fitting the stress dependence of $\dot{\varepsilon}_{\min } \Phi^{-1}$ for all creep tests in double logarithmic scales, $\log \left(\dot{\varepsilon}_{\min } \Phi^{-1}\right)=$ $\log (A)+n \log (\sigma)$, see Figure 6(b), gives $A=3.6 \cdot 10^{-10}$ $\mathrm{s}^{-1}$ and $n=6.1$ (compare with previous value $n=6.4$ ). Thus, consideration of the exact orientations of the specimens and including the specimens of orientations different from [001] at $\sigma=10 \mathrm{MPa}$ does not change $n$ significantly. It is remarkable that the dots for the high symmetry orientations [001] and [111] with high numbers of active octahedral slip systems, respectively, 8 and 6 (see Table II), practically coincide in Figure 6(b). On

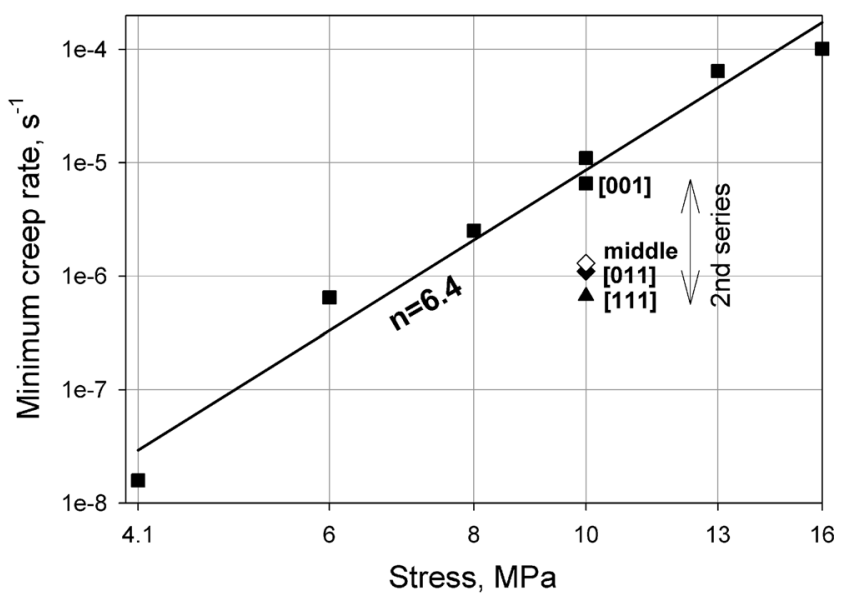

(b)

Fig. 5-Primary creep strain $(a)$ and minimum creep rate $(b)$ as function of the stress level. Black-filled squares are results of the 1st testing series, except the one marked as [001]. Other symbols correspond to the results of the 2nd testing series. 


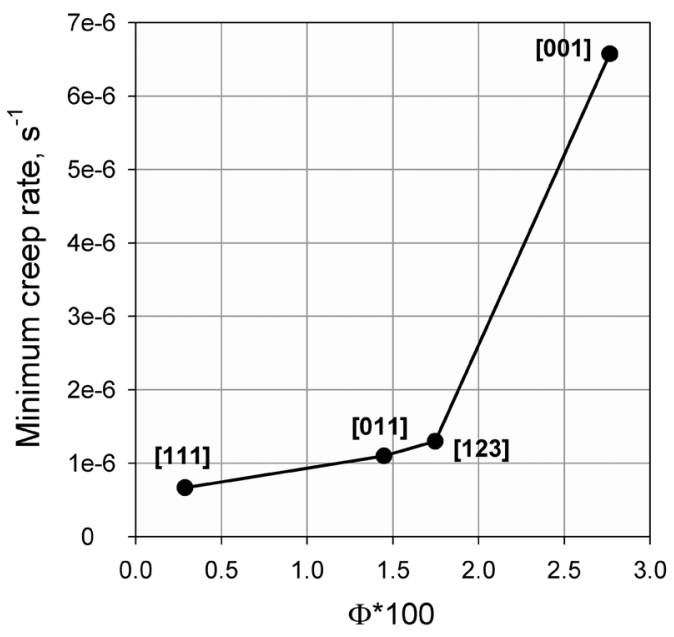

(a)

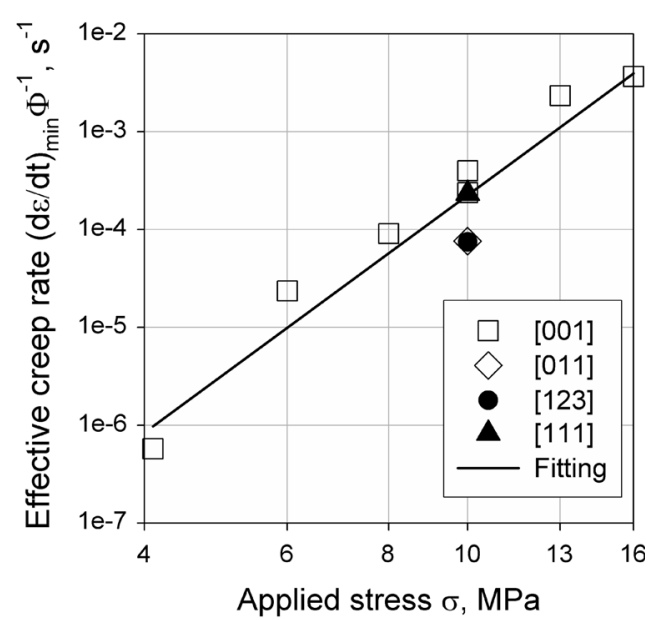

(b)

Fig. 6-Minimum creep rate $\dot{\varepsilon}_{\min } v s$ orientation factor $\Phi(a)$. Effective minimum creep $\dot{\varepsilon}_{\min } \Phi^{-1}$ for all specimens as a function of applied stress (b). The solid line in (b) is a fit with Eq. [5].

Table II. Elastic Force Factor $\boldsymbol{m}$ and Number of Active Deformation Systems for Different Deformation Mechanisms and Stress Directions

\begin{tabular}{|c|c|c|c|c|c|c|c|c|}
\hline \multirow[b]{3}{*}{ Deformation Mechanism } & \multicolumn{7}{|c|}{ Stress Direction } & \\
\hline & \multicolumn{2}{|c|}{ [001] } & \multicolumn{2}{|c|}{ [011] } & \multicolumn{2}{|c|}{$[123]$} & \multicolumn{2}{|c|}{ [111] } \\
\hline & $m$ & $s$ & $m$ & $s$ & $m^{*}$ & $s$ & $m$ & \\
\hline \multirow{2}{*}{ Octahedral slip } & 0.41 & 8 & 0.41 & 4 & 0.47 & 1 & 0.27 & \\
\hline & 0 & 4 & 0 & 8 & 0.35 & 2 & 0 & \\
\hline \multirow[t]{2}{*}{ Cubic slip } & 0 & 6 & 0.35 & 4 & 0.45 & 1 & 0.47 & \\
\hline & & & 0 & 2 & 0.40 & 1 & 0 & \\
\hline \multirow[t]{2}{*}{ Climb } & 0.5 & 4 & 1 & 1 & 0.89 & 1 & 0.67 & \\
\hline & 0 & 2 & 0.25 & 4 & 0.57 & 1 & 0 & \\
\hline$m_{c \lim b}^{\max } / m_{\text {oct.slip }}^{\max }$ & 1.2 & & 2.4 & & 1.9 & & 2.4 & \\
\hline
\end{tabular}

*For [123] stress direction, most of deformation systems have $m \neq 0$. Therefore, only the highest values of $m$ are presented. Not presented: $m \leq 0.29$ for octahedral slip, $m \leq 0.25$ for cubic slip, and $m \leq 0.32$ for climb.

the other side, the dots for the low symmetry orientations [011] and [123] with lower number of active octahedral slip systems, respectively, 4 and 2 (see Table II), deviate from the [001] to [111] trend in Figures 6(a) and (b).

\section{Recrystallization and Behavior}

Because recrystallization under HIP conditions is critical for the single-crystal blades, ruptured specimens were analyzed by EBSD. In Figures 7(a) through (d), one can see that the tendency for recrystallization apparently strongly depends on the specimen orientation and its shape after testing. In particular, the specimens [011] and [111] with lower $\psi$-values, respectively, 0.83 and $0.62 \mathrm{pct}$, and a rough rupture surface, which indicate deformation hardening during necking, totally recrystallized within the necking zone, see Figures 7(b) and (c). In contrast, the specimens [001] and [123] with higher $\psi$-values, respectively 99.8 and 92 pct, and thus a higher tendency to strain localization, show either no recrystallization (see the [001] specimen in Figure 7(a)), or only local recrystallization (see the [123] specimen in Figure 7(c)), in the necking zone.

However, an inspection of the cooling conditions after testing also suggests a possible correlation between the total time spent by the specimens at the high temperature and the recrystallization degree:

- The [001] specimen (Figure 7(a), no recrystallization) was tested for 2.2 hours and cooled down just after the test.

- The [011] specimen (Figure 7(b), total recrystallization) was tested for 7 hours and then held in the hot furnace at a temperature close to the testing temperature for 13 hours. Thus, the total exposure time at high temperature was 20 hours.

- The specimen [123] (Figure 7(c), partial recrystallization), was tested for 6.6 hours and then held in the hot furnace for 11.5 hours, thereby corresponding to a total exposure time at high temperature of 18.1 hours. 


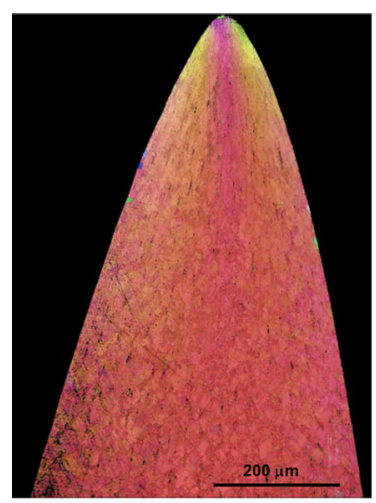

(a)

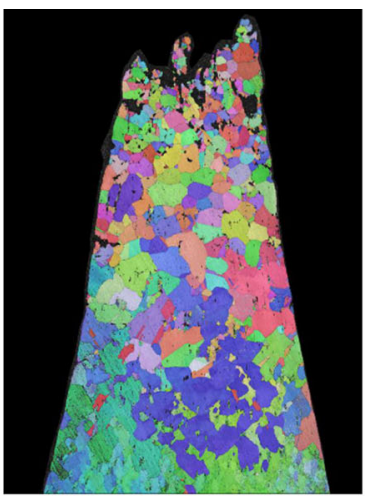

(b)

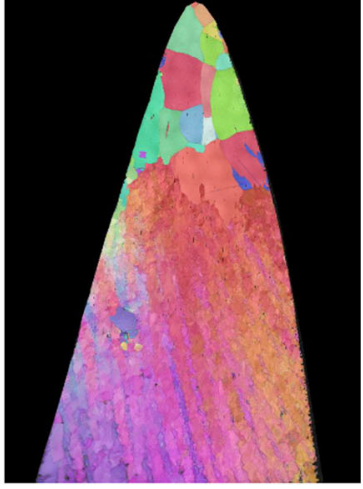

(c)

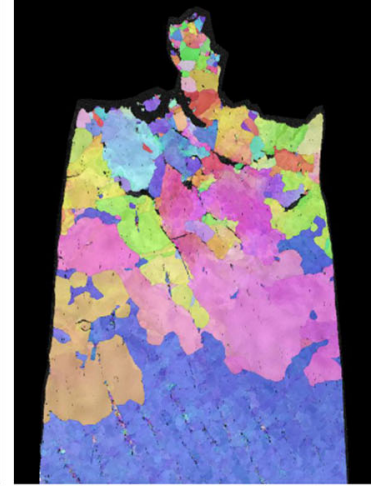

(d)

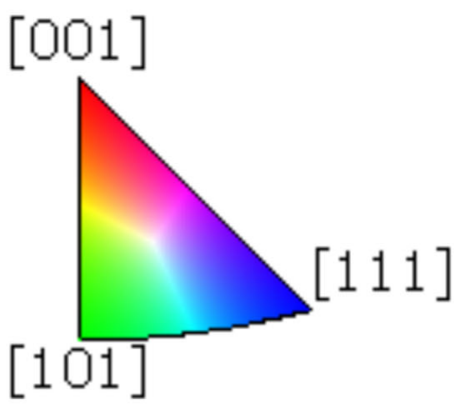

(e)

Fig. 7-Recrystallization behavior of specimen of different orientations. EBSD maps for specimens of different orientations tested until rupture under stress $10 \mathrm{MPa}$. Pattern quality + inverse pole figure orientation maps (IPFX). X is vertical direction. Cuts close to $\{011\}$. ( $a$ to $d)$ [001], [011], [123], and [111] specimens, respectively. (e) color code for orientation.

- The specimen [111] (Figure 7(d), total recrystallization) was tested for 22.2 hours and cooled down just after the test.

\section{Verification of the $\gamma^{\prime}$ Dissolution at Test Temperature $1288^{\circ} \mathrm{C}$}

In order to verify the $\gamma^{\prime}$ dissolution at $1288{ }^{\circ} \mathrm{C}$, the $\gamma / \gamma^{\prime}$ microstructure of the [011] specimen No. 11, which was quenched by air jet immediately after the test (see Table I), was investigated in SEM. In the dendritic regions, only $\{001\}$-faced $\gamma^{\prime}$ cuboids of about 0.1 to 0.15 $\mu \mathrm{m}$ in size were observed (see Figure 8(a)). These fine $\gamma^{\prime}$ particles precipitated during cooling. However, as shown in Figure 8(b), beside the fine $\gamma^{\prime}$ particles also large $\gamma^{\prime}$ precipitates of about 1 to $2 \mu \mathrm{m}$ in size were found in the interdendritic regions. These large $\gamma^{\prime}$ precipitates obviously coarsened during the creep test at $1288^{\circ} \mathrm{C}$.

It is remarkable that these $\gamma^{\prime}$ precipitates, which are too large for being bounded by coherent $\gamma / \gamma^{\prime}$ interfaces, are not faced by $\{001\}$-planes as would follow from the minimization of the energy of misfit stresses. Additional work is still needed to unambiguously identify the orientations of their interfaces. Nevertheless, according to molecular dynamics simulation ${ }^{[14]}$ they should be bounded by $\{111\}$ interfaces, for which the misfit dislocation networks minimize the interface energy $E_{\gamma / \gamma^{\prime}}$. Indeed, from the quoted simulations reported in Reference 14 follows $E_{\gamma / \gamma^{\prime}\{111\}}=32 \mathrm{~mJ} / \mathrm{m}^{2}$ for $\{111\}$ interfaces, whereas $E_{\gamma / \gamma^{\prime}\{001\}}=271 \mathrm{~mJ} / \mathrm{m}^{2}$ and $E_{\gamma / \gamma^{\prime}\{011\}}=240 \mathrm{~mJ} / \mathrm{m}^{2}$.

However, it must be mentioned that the volume fraction of these large $\gamma^{\prime}$-precipitates is below 1 vol pct. Therefore, their influence on the creep behavior of the alloy CMSX-4 at $1288{ }^{\circ} \mathrm{C}$ was neglected in the analysis of the active creep mechanisms, i.e., the material was considered as a single-phase $\gamma$-alloy.

\section{E. Deformation Mechanisms}

The EBSD investigations of deformed specimens presented traces of plastic deformation on octahedral slip systems. For example, in Figure 9, it is shown that the traces of shearing on (111)[101] slip system have maximum Schmid factor $m_{\text {slip }}=0.37$ in the [111] specimen tested until rupture under stress $10 \mathrm{MPa}$. The angle between the slip traces and the load axis is about $27 \mathrm{deg}$ and coincides with that calculated from the specimen orientation assuming octahedral glide. It should be mentioned that in [111] specimens one could theoretically also expect traces of cubic glide, which Schmid factor has value of 0.47 (see Table II) being very close to the maximum possible value equal to 0.5 . 


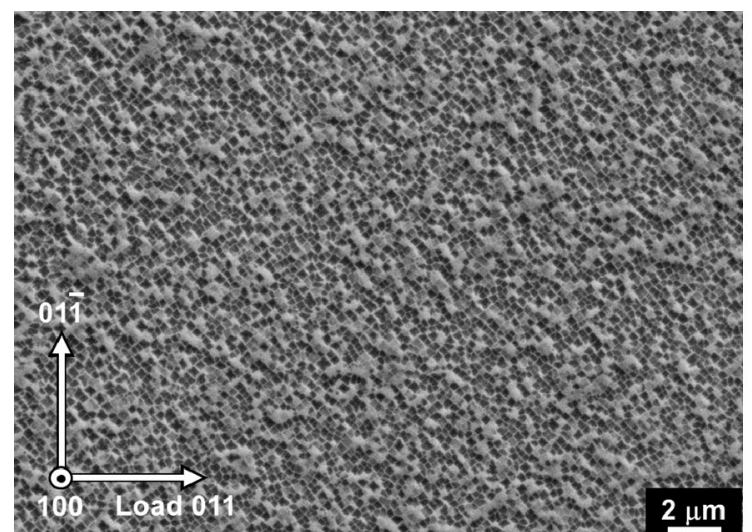

(a)

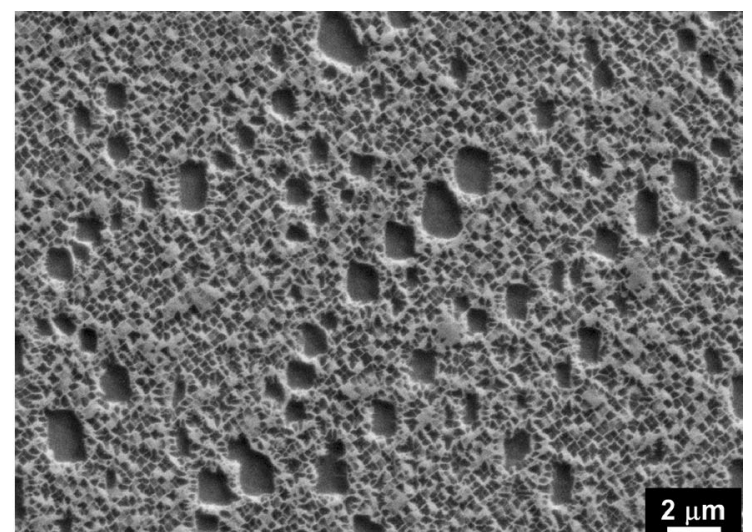

(b)

Fig. 8-The $\gamma / \gamma^{\prime}$-microstructure of the [011] specimen No. 11 (see Table I). SEM, SEI. (100) cut. The loading direction [011] is horizontal. (a) Fine $\gamma^{\prime}$-precipitates in a dendritic area. (b) Mixture of fine and large $\gamma^{\prime}$-precipitates in an interdendritic region.

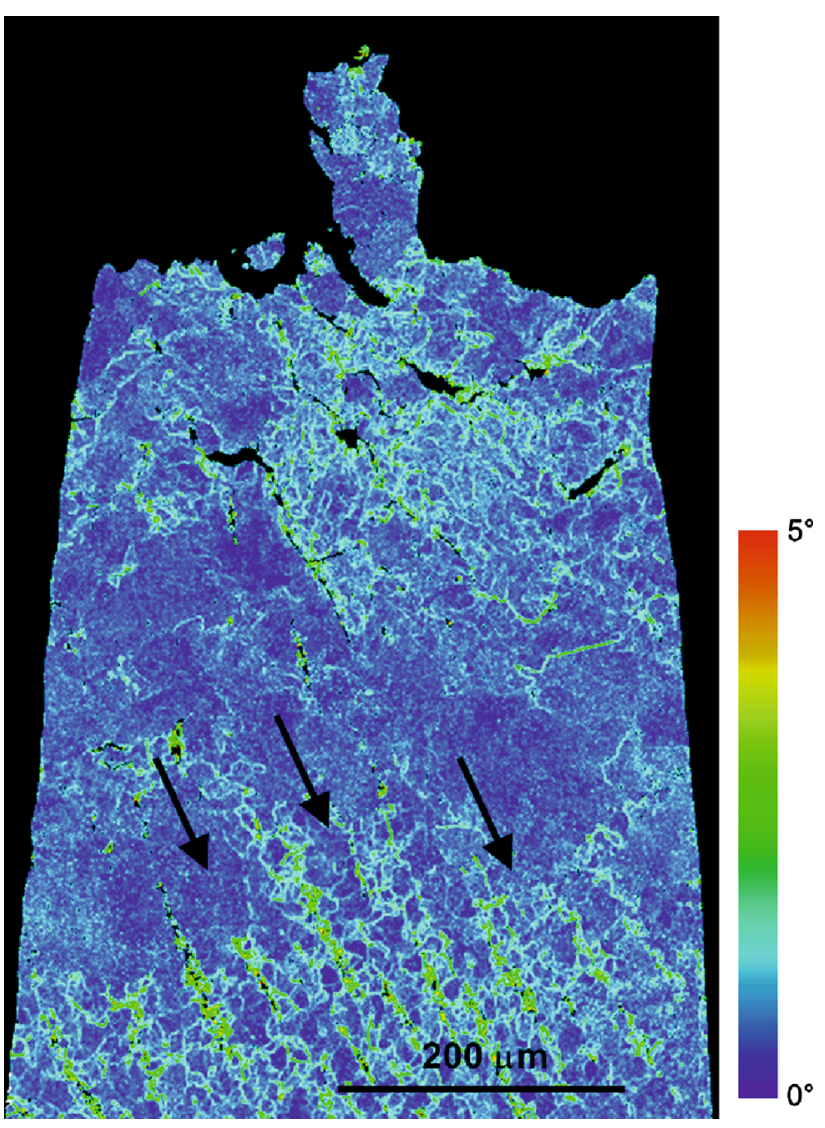

Fig. 9-Traces of shear deformation on (111)[101] slip system with maximum Schmid factor $m_{\text {slip }}=0.37$ in [111] specimen until rupture under stress $10 \mathrm{MPa}$. EBSD, misorientation kernel. The vertical bar is a color scale for the misorientation angle.

For a more detailed observation of the deformation mechanisms, selected specimens were investigated in TEM. The main point of interest was whether deformation takes place by dislocation glide or climb? Therefore, most TEM investigations were performed with [011] single crystals, for which climbing dislocations with Burgers vector $\vec{b}=a / 2[011]$ experience the strongest elastic force.

Figure 10(a) shows a TEM image of a [011] specimen creep deformed at $1288^{\circ} \mathrm{C}, 10 \mathrm{MPa}$ until rupture, and then cut on a longitudinal (110) plane. The specimen axis [110] marked a contour arrow is lying in the image plane. The thick bundle of dislocations is a Low Angle Boundary (LAB). The straight lines marked by solid arrows are traces of (11) $)$ glide planes and the trace of a (111) plane is visible as a horizontal line. Both planes are edge on, which explains why they appear as straight lines. The dislocations can glide on these octahedral planes under the elastic force because $\vec{i}_{\sigma} \cdot \vec{n}_{i} \neq 0$ $\left(\vec{i}_{\sigma}=1 / \sqrt{2}[110]:=\right.$ load axis, $\vec{n}_{i}:=$ plane normal) and they are ending in the LAB. It should be mentioned that the [011] specimen ruptured and thereafter was cooled without load. However, two dislocation loops visible in the middle of Figure 10(a) are stable despite the line tension. Their shrinking is obviously blocked by the $\gamma^{\prime}$-particles, which rapidly precipitated during cooling. Therefore, the configuration of these dislocations represents a polygonal line reproducing the $\gamma^{\prime}$-habit. The following question remains opened: were the dislocations visible near the LAB generated by this LAB acting as a source and thereafter frozen while expending or were they rather hindered during glide by this LAB, acting as an obstacle.

Because LABs are important for the dislocation dynamics, the LAB shown in Figure 10(b) was investigated in detail. It was identified that this network is formed by screw dislocations and consequently it is a twist boundary. Similar to that in Figure 10(a) one can see near the LAB gliding octahedral loops marked by solid arrows. TEM imaging under kinematical twobeam conditions showed that the areas right and left from the network cannot be brought simultaneously into the same imaging condition, which is a clear indication that they have different orientations. Measurements of the orientation difference between the crystals, on each side of the LAB gave an angle of about 


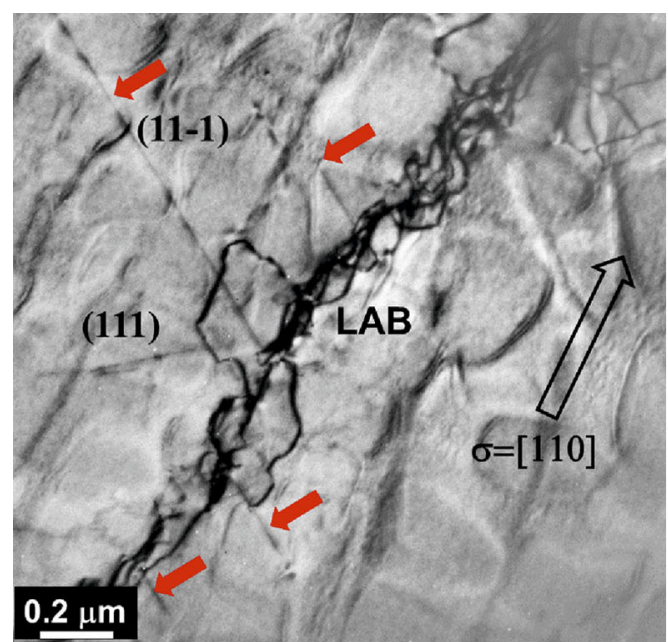

(a)

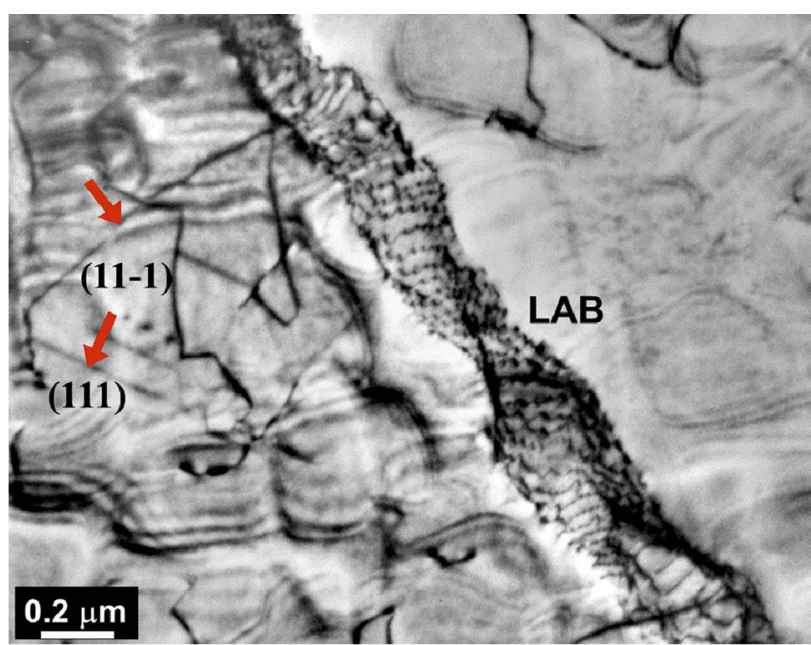

(b)

Fig. 10-TEM images of dislocation structures near Low Angle Boundaries (LABs) in a [011] single crystal of CMSX-4 after creep test at $1288{ }^{\circ} \mathrm{C} / 10 \mathrm{MPa}$ until rupture. $\overrightarrow{k_{0}}=[1 \overline{1} 0], \vec{g}=[\overline{1} \overline{1} 1]$. Distances from the rupture surface $5 \mathrm{~mm}(a)$ and $11.5 \mathrm{~mm}(b)$. A contour arrow in (a) shows the loading direction. Solid arrows in $(a, b)$ show traces of (111) or (111) glide planes.

0.6 to 0.8 deg, measured from the Kikuchi patterns and processed by the TOCA-software (Tools for Orientation Determination and Crystallographic Analysis). ${ }^{[15,16]}$ The rotation angle $\omega$, calculated from the mesh width $d \cong$ $20 \mathrm{~nm}$ and the magnitude of the Burgers vector $b=$ $0.25 \mathrm{~nm}$ gives $\omega=b / d \cong 0.7^{\circ}$, which fully confirms the diffractometric results. Such a LAB is rather a boundary separating different dendrites or their arms, which misorientation according to References 11 and 12 can be up to 2 to $3 \mathrm{deg}$, than a boundary between intradendritic mosaic blocks, which misorientation does not exceed a few of decimal parts of a degree.

In general, investigations of specimens of different orientations, [001], [011], [123], and [111] showed dislocations loops gliding on octahedral planes $\{111\}$ at LABs and no clear indication of dislocations climb.

\section{DISCUSSION}

\section{A. Creep Mechanism at Super-Solvus Temperature $1288^{\circ} \mathrm{C}$}

The solidus temperature $T_{s}$ of CMSX-4 is about $1340{ }^{\circ} \mathrm{C}=1613 \mathrm{~K}$, so the temperature of performed creep tests $1288^{\circ} \mathrm{C}=1561 \mathrm{~K}$ corresponds to a homologous temperature $T / T_{s}=0.97$.

The central question of our investigation was, which deformation mechanism is operating in a single-crystal superalloy at such a high homologous temperature? Investigation of this question has not only practical relevance for HIPing but also have a fundamental importance because it gives understanding how metals deform at temperatures close to their melting point. One can propose four possible mechanisms for this temperature: slip of dislocations on octahedral (mech. 1) or cubic planes (mech. 2), movement of dislocations by climb (mech. 3), and material flow by bulk diffusion, the so-called Nabarro-Herring (N-H) creep (mech. 4). Note that in the last case, the Low Angle Boundaries (LABs) can be assumed to substitute to the grain boundaries in the single crystal and thereby provide the necessary vacancy sources or sinks.

The first evidence for the dominance of a deformation mechanism is the specimen shape after testing. Here, a change of shape of the [011] specimen is interesting. First, in the cross section this specimen has two-fold symmetry and therefore it can shrink anisotropically, which can be interpreted as an indication of a certain deformation mechanism. Second, in this orientation all glide and climb mechanisms are possible because their force factors $m$ have non-zero values (see next section and Table II). Moreover climb, which is expected to be a deformation mechanism at high temperatures, have the highest possible value of $m_{\text {climb }}=1$ for this orientation. Therefore, in this section, we focus on the change of the cross section of a [011] specimen of gage length $l$ uniaxially deformed with the axial strain $\varepsilon_{z z}=\Delta l / l_{0}$.

The change of the specimen shape during deformation is defined by the macroscopic deformation gradient tensor $\boldsymbol{F}$. As usual in crystal plasticity (see e.g., Reference 17), a multiplicative decomposition of $\boldsymbol{F}$ in an elastic $\boldsymbol{E}$ and an inelastic part $\boldsymbol{P}, \boldsymbol{F}=\boldsymbol{E} \cdot \boldsymbol{P}$ is assumed. The rate $\dot{\boldsymbol{P}}$ of the inelastic part as a sum of the contributions of all slip systems $s$ has been obtained by Rice $^{[18]}$ :

$$
\dot{\boldsymbol{P}}=\left(\sum_{s} \dot{\gamma}_{s} \vec{m}_{s} \otimes \vec{n}_{s}\right) \cdot \boldsymbol{P},
$$

where $\vec{m}_{s}$ is the unit vector in the direction of the Burgers vector $\vec{b}_{s}, \vec{n}_{s}$ is the normal vector to the plane in which the dislocation segments move. In the case of gliding, $\vec{n}_{s}$ is the slip plane and $\dot{\gamma}_{s}=\frac{1}{V} b \dot{A}_{s}$ the shear rate due to the dislocations of the system $s$ sweeping a total area $A_{s}$ in a volume element $V$. In the case of climbing edge dislocations, $\dot{\gamma}_{s}$ corresponds rather to a stretching 
rate and the climbing plane is normal to the Burgers vector, that is $\vec{n}_{s}=\vec{m}_{s}$ (see, e.g., Reference 19).

In the general case, crystal rotations can take place, which lead to non-homogeneous deformations, and a Finite Element analysis of the whole specimen is necessary to evaluate the evolution of the specimen shape. To simplify things, we assume that these rotations can be neglected in the case of an ideally oriented [011] specimen. Within this assumption, the respective change of the specimen cross section due the four elementary deformation mechanisms introduced above and considered isolated will be estimated. Because of the orientation symmetry, Eq. [6] can be rewritten as

$$
\dot{\boldsymbol{P}}=\dot{\gamma}(t)\left(\sum_{s} \vec{m}_{\boldsymbol{s}} \otimes \vec{n}_{\boldsymbol{s}}\right) \cdot \boldsymbol{P},
$$

where $\dot{\gamma}$ is identical for all slip systems of the same type. In the absence of rotations, and due to the smallness of the elastic deformations, $\cong \boldsymbol{P}$, and the Eq. [7] can be easily integrated to finally obtain the components of $\boldsymbol{F}$ as function of the elongation $\varepsilon_{z z}$ in the specimen axes $\vec{x}=[100], \vec{y}=1 / \sqrt{2}[01 \overline{1}]$, and $\vec{z}=1 / \sqrt{2}[011]$ :

For octahedral glide $\langle 011\rangle\{11 \overline{1}\}$

$$
\begin{aligned}
\log \boldsymbol{F} & =\left[\begin{array}{ccc}
\log F_{x x} & 0 & 0 \\
0 & \log F_{y y} & 0 \\
0 & 0 & \log F_{z z}
\end{array}\right] \\
& =\log \left(1+\varepsilon_{z z}\right)\left[\begin{array}{ccc}
-1 & 0 & 0 \\
0 & 0 & 0 \\
0 & 0 & 1
\end{array}\right] .
\end{aligned}
$$

For cubic glide $\langle 011\rangle\{100\}$

$$
\begin{aligned}
\log \boldsymbol{F} & =\left[\begin{array}{ccc}
\log F_{x x} & 0 & 0 \\
0 & \log F_{y y} & 0 \\
0 & 0 & \log F_{z z}
\end{array}\right] \\
& =\log \left(1+\varepsilon_{z z}\right)\left[\begin{array}{ccc}
0 & 0 & 0 \\
0 & -1 & 0 \\
0 & 0 & 1
\end{array}\right] .
\end{aligned}
$$

Note that in the axial case considered above $F_{i i}=$ $1+\varepsilon_{i i}$ for the diagonal components $i$ of the engineering strain tensor $\varepsilon_{i j}$ in the specimen axes. If the strains are small, $\log F_{i i} \cong \varepsilon_{i i}$, which means that $\log \boldsymbol{F}$ amounts to the engineering strain tensor $\boldsymbol{\varepsilon}$. It should be mentioned that in [011] specimens, four octahedral and four cubic slip systems, respectively, are equally active, which lead to Eqs. [8] and [9] when their contributions are summed up.

In the case of climb, the problem of vacancies diffusion between the climbing dislocations and possible vacancy sources or sinks (other climbing dislocations, free surfaces, LABs) is complex. Six climb systems are possible with different force factors, which are summarized in Table III. Note that the activation of any of the climb systems with a non-vanishing force factor in the direction of their respective force factor would generate vacancies, which would lead to a vacancies excess and thus to opposite osmotic forces if effective vacancy sinks are not available. Having this in mind, the following mechanism seems most likely, in which the following two climb systems are active:

- [011](011), which experiences the maximum elastic force and generate vacancies,

- $[01 \overline{1}](01 \overline{1})$, which experiences only the osmotic force and consumes the vacancies generated by the first system.

If these two climb systems are equally active, which is likely at such a high temperature, since vacancies diffusion is expected to be sufficiently fast, the resulting deformation for climb on the $\langle 011\rangle\{011\}$ systems is

$$
\begin{aligned}
\log \boldsymbol{F} & =\left[\begin{array}{ccc}
\log F_{x x} & 0 & 0 \\
0 & \log F_{y y} & 0 \\
0 & 0 & \log F_{z z}
\end{array}\right] \\
& =\log \left(1+\varepsilon_{z z}\right)\left[\begin{array}{ccc}
0 & 0 & 0 \\
0 & -1 & 0 \\
0 & 0 & 1
\end{array}\right] .
\end{aligned}
$$

It is isochoric and proportional to that caused by cubic glide (see Eq. [9]).

For creep by bulk diffusion alone (mech. 4), which is isotropic in cubic crystals, one gets the macroscopic strain tensor simply from the isotropy and incompressibility conditions, which respectively, impose $F_{x x}=F_{y y}$ and $\operatorname{det} \boldsymbol{F}=F_{x x} F_{y y} F_{z z}=1$.

Thus, for bulk diffusion

$$
\begin{aligned}
\log \boldsymbol{F} & =\left[\begin{array}{ccc}
\log F_{x x} & 0 & 0 \\
0 & \log F_{y y} & 0 \\
0 & 0 & \log F_{z z}
\end{array}\right] \\
& =\log \left(1+\varepsilon_{z z}\right)\left[\begin{array}{ccc}
-1 / 2 & 0 & 0 \\
0 & -1 / 2 & 0 \\
0 & 0 & 1
\end{array}\right] .
\end{aligned}
$$

The equation of the deformed specimen cross section in polar coordinates is derived in "Appendix A." For example, in the case of a deformation along the $x$-direction, we obtain

$$
r(\varphi)=\frac{R F_{x x}}{\sqrt{1+\sin ^{2} \varphi\left(F_{x x}^{2}-1\right)}},
$$

where $R$ is the initial radius of the specimen and $\varphi$ is the angle between the radial direction and $\vec{x}=[100]$.

Table III. Elastic Force Factors for the Six Climb Systems in the Case of a [011] Specimen

\begin{tabular}{lcccccr}
\hline System & {$[011](011)$} & {$[01 \overline{1}](01 \overline{1})$} & {$[101](101)$} & {$[\overline{1} 01](\overline{1} 01)$} & {$[\overline{1} 10](\overline{1} 10)$} & {$[110](110)$} \\
\hline Force factor & 1 & 0 & 0.25 & 0.25 & 0.25 & 0.25 \\
\hline
\end{tabular}


In the case of small strains, the previous equation can be simplified as

$$
r(\varphi)=R\left(1+\varepsilon_{x x} \cos ^{2} \varphi\right) .
$$

Figure 2(a) presents the results of calculation (solid line) using Eq. [13] for a [011] specimen deformed up to creep strain $\varepsilon_{z z}=5.1$ pct under assumption of octahedral glide. It is assumed that $\varepsilon_{x x} \cong \log F_{x x}=-\log F_{z z} \cong$ $-\varepsilon_{z z}$ and $\varepsilon_{y y}=0$, see Reference 8 . It is seen that the prediction fits well with the experiment. The predicted contour of the cross section practically coincides with the measured dots.

In the specimen axes, the change of an initial cross section $S_{0}$ is given by the relation $S=S_{0} / F_{z z}$ and thus $\psi=1-1 / F_{z z}$. In the case of a ruptured [011] specimen with $\psi=83$ pct, the strain required in Eq. [12] can be determined from the equation:

$$
\psi=1-F_{x x} F_{y y},
$$

which follows from the incompressibility condition. For octahedral glide, Eq. [8] implies $F_{y y}=1$ and it results from Eq. [14] that $F_{x x}=1-\psi$, while for cubic glide and climb it is opposite, i.e., $F_{x x}=1$ and $F_{y y}=1-\psi$. For isotropic $\mathrm{N}-\mathrm{H}$ creep the specimen cross section remains circular with diameter $d=d_{0} \sqrt{1-\psi}$.

Figure 2(b) shows the specimen cross sections for the ruptured [011] specimen predicted assuming the different creep mechanisms. The comparison of the specimen shape in Figures 1(b) and (c) and the predictions for the cross section in Figure 2(b) unambiguously support octahedral glide as the dominant creep mechanism. It can be seen from Figure 2(b) that only the cross-sectional shape predicted under assumption of octahedral glide fits with the experimentally observed one.

The second evidence for deformation mechanism is observed anisotropy of the creep rate. Here the N-H model should be at once rejected because bulk diffusion in cubic crystals is isotropic. ${ }^{[20]}$ For glide and climb, the creep anisotropy can be discussed considering two factors: the magnitudes of elastic forces acting on moving dislocations and number of active deformation systems contributing to the macroscopic creep strain. The first "force factor" is usually treated as the Schmid factor. But the Schmid factor concept is not sufficient for such an analysis, because it considers only the translation of a dislocation along the glide plane (shear), but not the diffusional climb of a dislocation out of the glide plane. This becomes possible with the normalized elastic force concept applying to a dislocation translating in any direction $\vec{u}$.

The elastic $\vec{F}_{e l} / L$ force acting on a dislocation segment of length $L$ with direction $\vec{\xi}$ and Burgers vector $\vec{b}$ under stresses described by the stress tensor $\hat{\sigma}$ is given by the Peach-Koehler formula:

$$
\frac{\vec{F}_{e l}}{L}=\vec{b} \cdot \hat{\sigma} \times \vec{\xi}
$$

For the case of uniaxial loading by stress $\sigma$, the Eq. [15] takes the form:

$$
\frac{\vec{F}_{e l}}{L}=b \sigma\left(\overrightarrow{i_{b}} \cdot \vec{i}_{\sigma}\right) \overrightarrow{i_{\sigma}} \times \vec{\xi}
$$

where $\vec{i}_{b}$ and $\vec{i}_{\sigma}$ are, respectively, the unit vectors in the directions of $\vec{b}$ and of the loading axis.

From Eq. [16] follows that a normalized elastic force $F_{e l, u} /(L b \sigma)$ driving a dislocation in the direction $\vec{u}$ is

$$
\frac{F_{e l, u}}{L b \sigma}=\frac{\left(\vec{F}_{e l} \cdot \vec{u}\right)}{L b \sigma}=m
$$

with

$$
m=\left(\overrightarrow{i_{b}} \cdot \overrightarrow{i_{\sigma}}\right)\left(\vec{n} \cdot \overrightarrow{i_{\sigma}}\right),
$$

where $\vec{n}=\vec{\xi} \times \vec{u}$ is the normal to the movement plane.

It is seen from [18] that for the case of a gliding dislocation, $m$ is simply the well-known Schmid factor $m_{s l i p}$, while for the case of a climbing edge dislocation with $\overrightarrow{i_{b}}=\vec{n}$

$$
m_{\text {climb }}=\left(\overrightarrow{i_{b}} \cdot \overrightarrow{i_{\sigma}}\right)^{2} .
$$

The Schmid factor is originally defined for a shear deformation system but the factor $m$ defined by [18] is valid for an arbitrary deformation system and can be considered as a generalized Schmid factor, as it is used in, e.g., References 21, 22. Its physical meaning is a normalized elastic force acting on a dislocation of a unit length. For all types of gliding dislocations $0 \leq m_{\text {slip }} \leq 0.5$, for screw dislocations $m_{\text {climb }}=0$ (they cannot climb) and for climbing edge dislocations $0 \leq m_{\text {climb }} \leq 1$.

For creep kinetics, the number of active deformation systems $s$ and the values of corresponding elastic force factors $m$ are important. Table II gives $m$ and $s$ for dislocations with the Burgers vectors $a / 2\langle 011\rangle$ for three stress directions [001], [011], and [111], and for three deformation mechanisms: for octahedral slip, for cubic slip, and for climb of edge dislocations along $\{011\}$ planes. It should be considered that the effect of $m$ is very strong, because it contributes to the creep rate $\dot{\varepsilon}$ as $m^{n+1}$ ( $n$ is the stress exponent), whereas $s$ contributes as a multiplicative pre-factor, see Eq. [3]. It is shown in Table II that for octahedral slip $m$ decreases from 0.41 for [001] to 0.27 for [111], which fits with the observed decrease of the creep rate. For cubic slip, the change of $m$ is opposite, from 0 for [001] to 0.47 for [111], which is in contradiction to the observed creep anisotropy. For climb, $m$ is generally larger than for slip and reaches 1 for [011] orientation, which is the maximum possible value. Therefore, one could expect that climb should be dominant, especially at such a high homological temperature $T / T_{s} \approx 0.97$, where diffusion is fast. However, the mobility of climbing dislocations can be much lower than that of gliding dislocations. Indeed, checking the 
Table IV. Checklist of the Creep Mechanisms

\begin{tabular}{|c|c|c|c|c|}
\hline \multirow[b]{2}{*}{ Criterion } & \multicolumn{4}{|c|}{ Deformation Mechanism } \\
\hline & OCTAHEDRAL SLIP & Cubic Slip & Climb & N-H Creep \\
\hline Necking anisotropy & $\oplus$ & $\ominus$ & $\ominus$ & $\ominus$ \\
\hline Creep anisotropy & $\oplus$ & $\ominus$ & $\ominus$ & $\ominus$ \\
\hline Stress exponent $n$ & & & & $\ominus$ \\
\hline Trace analysis & $\oplus$ & & & \\
\hline TEM & $\oplus$ & $\ominus$ & $\ominus$ & \\
\hline Validation & $\oplus \oplus \oplus \oplus$ & $\theta \ominus \ominus$ & $\theta \ominus \ominus$ & $\ominus \ominus \ominus$ \\
\hline
\end{tabular}

The symbols $\oplus$ and $\ominus$ indicate findings that agree with or contradict, respectively, the considered deformation mechanism.

orientation dependence of $m_{\text {climb }}$ in Table II shows that the observed creep anisotropy does not fit with climb.

The third evidence for deformation mechanism is the stress exponent $n$ in the Norton power law. According to our results, $n$ is equal to about 6 . Such a value of the stress exponent could be referred both to glide and to climb. In the temperature interval $800{ }^{\circ} \mathrm{C}$ to $1100{ }^{\circ} \mathrm{C}$ where glide is important, the stress exponent for CMSX-4 changes in the range between about 7 and 13. ${ }^{[23]}$ Numerous dislocation models developed for recovery climb controlled creep given $n=3$ but experimentally for many pure metals and alloys $n=4$ to $5{ }^{[24]} \mathrm{So}$, the value $n=6$ is between the values reported for glide and climb. But $n=6$ does not fit to the N-H model, which leads to $n=1$.

The fourth evidence for deformation mechanism is provided by the results of the microstructural investigations of specimens after creep. They unambiguously support octahedral glide. Traces of octahedral glide were observed in SEM by EBSD, as well as dislocation loops gliding on octahedral planes near LABs were found in TEM. Regarding cubic slip, it was suggested in References 25, 26 that the apparent cubic slip in nickel-based superalloys is not due to genuine glide of dislocations on $\{100\}$ planes, but due to the obstacle to dislocation glide formed by the $\{001\}$ interfaces bordering the matrix channels. Thereby, the dislocations glide through the channels on octahedral planes, but when they meet an interface the screw segments can cross slip on another octahedral plane and resume propagation, provided the resolved shear stresses on this plane are positive. This process is repeated at the opposite interfaces of the channel, resulting in a zigzag path with an "average glide plane" $\{100\}$. Another explanation for the cubic slip effect was proposed in References 27, 28. Accordingly, this effect is rather due to a lack of hardening by the dislocation segments deposited in the particle interfaces, when specific combinations of slip systems (specially for $<111>$ specimens) are activated. In both cases, the cubic slip phenomenon relies on the existence of large cubic precipitates. However, at the considered temperature of $1288^{\circ} \mathrm{C}$ the $\gamma^{\prime}$-precipitates are dissolved, i.e., the channels disappear and this quasi-cubic slip does not occur.

The results of all investigations are summarized in Table IV. One can see that they all support octahedral glide, four " + ," as the dominant strain-producing mechanism and no indications of other possible mechanisms (cubic glide, climb, and N-H creep) were found. Climb, which is expected to be active at high temperatures, is not the dominant contribution to the creep strain. However, it could still be a critical link in the deformation mechanisms chain, e.g., as a recovery mechanism.

\section{B. Dependence of the Anisotropy of the Creep Strength on the Temperature}

As noted in Section III-B, the observed creep behavior at $1288^{\circ} \mathrm{C}$ is more anisotropic than at lower temperature, which might appear surprising at first sight. Firstly, it should be recalled that most (if not all) published creep data for single-crystal superalloys were obtained at temperatures where the alloy is strengthened by the $\gamma^{\prime}$-phase. Secondly, under creep conditions, the $\gamma / \gamma^{\prime}$ microstructure can deform by more mechanisms than the pure $\gamma$ phase. Indeed, the following deformation mechanisms were reported in superalloys (without being exhaustive):

(a) $0 \overline{1} 1\{111\}$ octahedral glide ${ }^{[29]}$ or cubic glide $0 \overline{1} 1\{100\}^{[25,26]}$ in the $\gamma$-matrix,

(b) $\overline{1} 12\{111\}$ (see, e.g., Reference 30) or $0 \overline{1} 1\{111\}$ (see, e.g., References 29, 30) viscous glide and $100\{100\}$ climb (see, e.g., Reference 31) in the $\gamma^{\prime}$-precipitates,

(c) $0 \overline{1} 1\{001\}$ combined glide-climb (see, e.g., Reference 31) along the $\gamma / \gamma^{\prime}$-interfaces.

Clearly, the mechanisms under b and c, like cubic slip as argued in the previous section, require a significant volume fraction of the $\gamma^{\prime}$ phase to yield a noticeable contribution to the overall creep strain. With varying temperatures, the dominating mechanisms to overcome the $\gamma^{\prime}$ precipitates change and the creep anisotropy changes in accordance. For example, at $750{ }^{\circ} \mathrm{C}$ the [001] single crystals of CMSX-4 have the highest creep strength but at $950{ }^{\circ} \mathrm{C}$ the [111] crystals have the longest time to rupture (see Reference 13). As a rule of thumb, the number of available mechanisms to overcome obstacles increases with temperature due to faster diffusion, which in turn lowers the degree of anisotropy. However, above the $\gamma^{\prime}$ solvus temperature $T_{\text {solv }}$, the main obstacles to dislocation glide, i.e., the $\gamma^{\prime}$-precipitates, are absent and the anisotropy is then only controlled by octahedral glide. 


\section{Relevance of the Obtained Creep Data for Modeling the Pore Annihilation During HIP}

Regarding the main application of the presented investigations, i.e., the HIP process, one could object that during HIP the material is held under pressure while all tests were performed under tension. However, around a pore, the stress state is not hydrostatic. Indeed, a material volume adjacent to a spherical pore experiences the superposition of a tensile stress along the radial direction from the pore center with a $2 \mathrm{D}$ compression by tangential stresses according to the isotropic solution. Therefore, the deviatoric stress tensor, which controls plastic deformation, corresponds to a uniaxial tension state along the radial direction. Under such a stress state the material plastically expands towards the pore center, which results in pore shrinkage. The performed tensile creep tests are thus close to these stress and deformation modes.

\section{CONCLUSIONS}

1. The creep behavior of the single-crystal nickelbased superalloy CMSX-4 was investigated at super-solvus $1288^{\circ} \mathrm{C}$ (homologous temperature $T / T_{s} \approx 0.97$ ), which corresponds to HIP conditions commercially used for this superalloy. It was found that at this super-solvus temperature, where no $\gamma^{\prime}$-strengthening occurs, the superalloy is very soft and rapidly deforms under stresses between 4 and $16 \mathrm{MPa}$. The creep data were used to calibrate the creep law implemented in a crystal viscoplasticity model describing the kinetics of porosity annihilation in CMSX-4 during commercial HIP. ${ }^{[6,7]}$

2. The creep behavior of the superalloy CMSX-4 at super-solvus temperature was found to be very anisotropic. The average creep rate of [001] and [111] crystals differs by factor 11.5 , which is higher than that at lower temperatures. The [011] and [123] crystals showed similar creep rates between those for [001] and [111]. This observed anisotropy can be reasonably well rationalized by the theory of crystal plasticity with octahedral glide.

3. The necking and recrystallization behavior was found to be dependent on the crystal orientation. The cross section of [001] crystals shrinks isotropically and approaches zero, $\psi=99.8 \mathrm{pct}$, but these crystals do not recrystallize. The [011] and [123] crystals showed strong and very anisotropic necking accompanied by recrystallization. The [111] crystal showed isotropic necking, it shrank less than other orientations but totally recrystallized within the necking zone. On the other side, the recrystallization behavior of the investigated specimens was also found to correlate with the exposure time at high temperature: a longer exposure time corresponding to a larger recrystallized region. Hence, more work is needed to unambiguously identify the influence factors for recrystallization during creep at $1288{ }^{\circ} \mathrm{C}$.

4. Several criteria including creep anisotropy, the change of the cross-sectional shape during creep, stress exponent, and electron microscopy unambiguously supported octahedral glide as the dominant strain-producing mechanism. No indications of other possible mechanisms (cubic glide, climb, and $\mathrm{N}-\mathrm{H}$ creep) were found.

\section{ACKNOWLEDGMENTS}

This work was supported by the German Research Foundation DFG (Projects EP 136/1-1 and FE933/ 2-1) and the French National Research Agency ANR (Projects ANR15-MERA-000-03 and ANR15-MERA0003-04).

\section{APPENDIX A}

Equation for the Cross-Sectional Shape of [011] Specimen Deformed by Octahedral Glide

In this section, the equations giving the shape of the cross section of the specimen are derived in the case in which the specimen is only deformed along one of the principal axes $\vec{x}$ or $\vec{y}$, which is true in the case of $\langle 011\rangle$ specimens under either octahedral glide, cubic glide, or climbing.

For instance, if the deformation occurs along the direction $x$ with the strain $\varepsilon_{x x}=F_{x x}-1$, a material point on the specimen surface of initial radius $R$ moves along the $x$-direction and its polar coordinates $(r, \varphi)$ after deformation satisfy the equations (see Figure A1)

$$
\begin{gathered}
R^{2}=(r \sin \varphi)^{2}+l^{2}, \\
r^{2}=(r \sin \varphi)^{2}+F_{x x}^{2} l^{2} .
\end{gathered}
$$

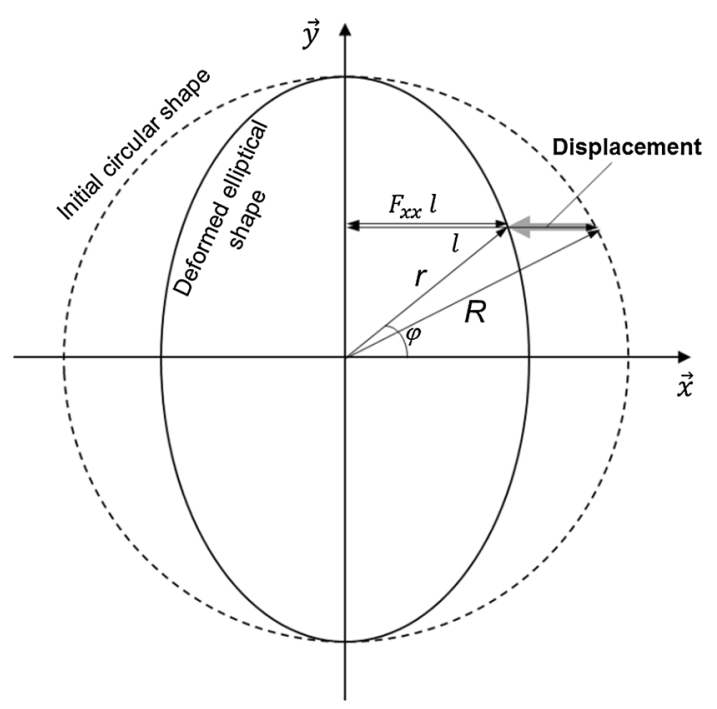

Fig. A1-Notations for the change of shape of the $(x, y)$ cross section. 
Multiplying [1] by $F_{x x}^{2}$ and subtracting [2] from [1] ones gets

$$
F_{x x}^{2} R^{2}-r^{2}=(r \sin \varphi)^{2}\left[F_{x x}^{2}-1\right] .
$$

From [3] follows:

$$
r(\varphi)=\frac{R F_{x x}}{\sqrt{1+\sin ^{2} \varphi\left(F_{x x}^{2}-1\right)}} .
$$

Equation [4] is the equation of an ellipse in polar coordinates. It can be written using $F_{x x}=1+\varepsilon_{x x}$ as follows:

$$
r(\varphi)=\frac{R\left(1+\varepsilon_{x x}\right)}{\sqrt{1+\sin ^{2} \varphi\left[\left(1+\varepsilon_{x x}\right)^{2}-1\right]}} .
$$

Similarly, if the cross section is only deformed in the $y$-direction (case of cubic slip or climb), we have

$$
r(\varphi)=\frac{R F_{y y}}{\sqrt{1+\cos ^{2} \varphi\left(F_{y y}^{2}-1\right)}}
$$

or

$$
r(\varphi)=\frac{R\left(1+\varepsilon_{y y}\right)}{\sqrt{1+\cos ^{2} \varphi\left[\left(1+\varepsilon_{y y}\right)^{2}-1\right]}} .
$$

\section{REFERENCES}

1. A. Epishin, T. Link, U. Brückner, and P.D. Portella: Seventh Liège Conference on Materials for Advanced Power Engineering, 2002, pp. 217-26.

2. K.P.L. Fullagar, R.W. Broomfield, M. Hulands, K. Harris, G.L. Erickson, and S.L. Sikkenga: Trans. ASME, 1996, vol. 118, pp. 380-88.

3. K. Harris, G.L. Erickson, S.L. Sikkenga, W.D. Brentnall, J.M. Aurrecoechea, and K.G. Kubarych: Seventh International Symposium on Superalloys, 1992, pp. 297-306.

4. J. Cormier, X. Milhet, and J. Mendez: Acta Mater., 2007, vol. 55, pp. $6250-59$.
5. J.-B. le Graverend, J. Cormier, F. Gallerneau, S. Kruch, and J. Mendez: Mater. Des., 2014, vol. 56, pp. 990-97.

6. A. Epishin, B. Fedelich, T. Link, T. Feldmann, and I.L. Svetlov: Mater. Sci. Eng. A, 2013, vol. 586, pp. 342-49.

7. A.I. Epishin, T. Link, B. Fedelich, I.I. Svetlov, and E.R. Golubovskiy: MATEC Web of Conferences, 2014, vol. 14, AN 08003.

8. http://cannonmuskegon.com/products/vacuum-alloys/.

9. B.C. Wilson, J.A. Hickman, and G.E. Fuchs: JOM, 2003, vol. 55 (3), pp. 35-40.

10. R.E. Shalin, I.L. Svetlov, E.B. Kachanov, V.N. Toloraya, and O.S. Gavrilin: Single-Crystals of Nickel-Base Superalloys, Mashinostroeniye, Moscow, 1997 (in Russian).

11. U. Bruckner, A. Epishin, and T. Link: Acta Mater., 1997, vol. 45, pp. 5223-31.

12. U. Bruckner, A. Epishin, T. Link, and K. Dressel: Mater. Sci. Eng. A, 1991, vol. A247, pp. 23-31.

13. C.K. Bullough, M. Toulios, M. Oehl, and P. Lukas: Sixth Liege Conference on Materials for Advanced Power Engineering, 1998, pp. $861-78$.

14. T. Thu and C.-Y. Wang: Phys. Rev. B, 2005, vol. 72, pp. 014111/ $1-014111 / 6$.

15. S.J. Zaefferer: Appl. Cryst., 2000, vol. 33, pp. 10-25.

16. S. Zaefferer: Adv. Imaging Electron Phys., 2002, vol. 125, pp. 355-415.

17. F. Roters, P. Eisenlohr, L. Hantcherli, D.D. Tjahjanto, T.R. Bieler, and D. Raabe: Acta Mater., 2010, vol. 58, pp. 11521211.

18. J.R. Rice: J. Mech. Phys. Solids, 1971, vol. 19, pp. 43355 .

19. S. Yuana, M. Huanga, Y. Zhua, and Z. Lia: Mech. Mater., 2018, vol. 118 , pp. $44-61$.

20. H. Mehrer: Diffusion in Solids, Springer, New York, 2007.

21. F. Mompiou, L. Bresson, P. Cordier, and D. Caillard: Philos. Mag., 2003, vol. 83, pp. 3133-57.

22. L. Agudo Jácome, P. Nörtershäuser, C. Somsen, A. Dlouhý, and G. Eggeler: Acta Mater., 2014, vol. 69, pp. 246-64.

23. W. Schneider, J. Hammer, and H. Mughrabi: Seventh International Symposium on Superalloys, 1992, pp. 589-98.

24. J. Weertman and J. R. Weertman: Physical Metallurgy, North-Holland Physics Publishing, Amsterdam, vol. 2, 1983, Chapter 20, pp. 1309-40.

25. V. Sass and M. Feller-Kniepmeier: Mater. Sci. Eng. A, 1998, vol. 245, pp. 19-28.

26. D. Bettge and W. Österle: Scripta Mater., 1999, vol. 40, pp. 389-95.

27. A. Vattré, B. Devincre, and A. Roos: Acta Mater., 2010, vol. 58, pp. $1938-51$

28. A. Vattré and B. Fedelich: Mech. Mater., 2011, vol. 43, pp. $930-51$.

29. T. Link and M. Feller-Kniepmeier: Z. Metallkde, 1988, vol. 79, pp. 381-87.

30. V. Sass, U. Glatzel, and M. Feller-Kniepmeier: Acta Mater., 1996, vol. 44, pp. 1967-77.

31. A. Epishin and T. Link: Philos. Mag., 2004, vol. 84, pp. 1979-2000. 